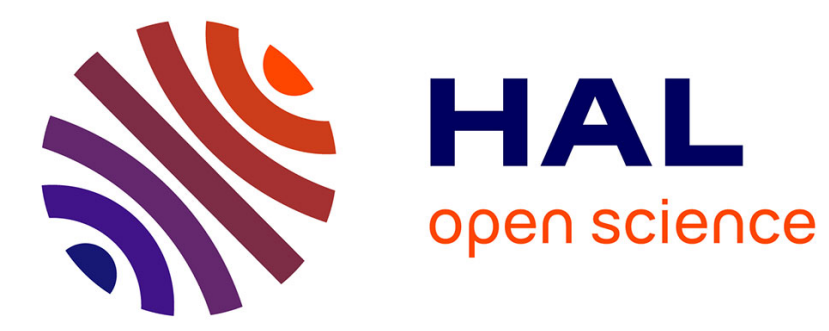

\title{
Conduction heat transfer in a cylindrical dielectric barrier discharge reactor
}

\author{
H. Sadat, N. Dubus, L. Pinard, J.M. Tatibouet, J. Barrault
}

\section{To cite this version:}

H. Sadat, N. Dubus, L. Pinard, J.M. Tatibouet, J. Barrault. Conduction heat transfer in a cylindrical dielectric barrier discharge reactor. Applied Thermal Engineering, 2009, 29 (5-6), pp.1259-1263. 10.1016/j.applthermaleng.2008.06.006 . hal-00630272

\section{HAL Id: hal-00630272 \\ https://hal.science/hal-00630272}

Submitted on 8 Oct 2011

HAL is a multi-disciplinary open access archive for the deposit and dissemination of scientific research documents, whether they are published or not. The documents may come from teaching and research institutions in France or abroad, or from public or private research centers.
L'archive ouverte pluridisciplinaire HAL, est destinée au dépôt et à la diffusion de documents scientifiques de niveau recherche, publiés ou non, émanant des établissements d'enseignement et de recherche français ou étrangers, des laboratoires publics ou privés. 


\section{Accepted Manuscript}

Conduction heat transfer in a cylindrical dielectric barrier discharge reactor

\section{APPLIED}

THERMAL

ENGINEERING

H. Sadat, N. Dubus, L. Pinard, J.M. Tatibouet, J. Barrault

PII:

S1359-4311(08)00263-9

DOI:

10.1016/j.applthermaleng.2008.06.006

Reference:

ATE 2533

To appear in:

Applied Thermal Engineering

Received Date: $\quad 16$ July 2007

Revised Date: $\quad 17$ April 2008

Accepted Date: 2 June 2008

Please cite this article as: H. Sadat, N. Dubus, L. Pinard, J.M. Tatibouet, J. Barrault, Conduction heat transfer in a cylindrical dielectric barrier discharge reactor, Applied Thermal Engineering (2008), doi: 10.1016/j.applthermaleng. 2008.06.006

This is a PDF file of an unedited manuscript that has been accepted for publication. As a service to our customers we are providing this early version of the manuscript. The manuscript will undergo copyediting, typesetting, and review of the resulting proof before it is published in its final form. Please note that during the production process errors may be discovered which could affect the content, and all legal disclaimers that apply to the journal pertain. 


\title{
Conduction heat transfer in a cylindrical dielectric barrier discharge reactor
}

\author{
H.Sadat ${ }^{1}$, N.Dubus ${ }^{1}$, L.Pinard ${ }^{2}$, J.M.Tatibouet ${ }^{2}$ and J.Barrault ${ }^{2}$ \\ ${ }^{1}$ Laboratoire d'Etudes Thermiques, Université de Poitiers, 40 Avenue du Recteur Pineau, \\ 86022 Poitiers France \\ ${ }^{2}$ Laboratoire en catalyse et chimie organique, Université de Poitiers, 40 Avenue du Recteur \\ Pineau, 86022 Poitiers France \\ hamou.sadat@univ-poitiers.fr
}

\begin{abstract}
:
The thermal behaviour of a dielectric barrier discharge reactor is studied. The experimental tests are performed on a laboratory reactor with two working fluids: helium and air. A simple heat conduction model for calculating the heat loss is developed. By using temperature measurements in the internal and external electrodes, a thermal resistance of the reactor is defined. Finally, the percentage of the input power that is dissipated to the environment is given.
\end{abstract}

Keywords: DBD reactor, heat conduction, thermal resistance

\section{Nomenclature:}

p generated power per unit volume

$\left(\mathrm{W} \cdot \mathrm{m}^{-3}\right)$

$\mathrm{P} \quad$ total generated power

(W)

$\eta \quad$ percentage of input power dissipated by heat conduction. ( $\%$

$\lambda \quad$ thermal conductivity

$\left(\mathrm{W} \cdot \mathrm{K}^{-1} \cdot \mathrm{m}^{-1}\right)$

$\mathrm{R}_{\mathrm{T}} \quad$ thermal resistance

$\mathrm{R}_{\mathrm{G}}$ thermal resistance of the annular gas gap

$\left(\mathrm{K} . \mathrm{W}^{-1}\right)$

$\left(\mathrm{K} . \mathrm{W}^{-1}\right)$

$\mathrm{R}_{\mathrm{i}} \quad$ internal radius of DBD reactor

(m)

$\mathrm{R}_{0} \quad$ internal radius of the glass tube

(m)

$\mathrm{r}$ radius

(m)

L length of the outer electrode

(m)

$\mathrm{T}_{\mathrm{e}} \quad$ temperature at the surface of the internal electrode

$\mathrm{T}_{\mathrm{o}} \quad$ temperature at the inner surface of the glass

$\mathrm{T}_{\mathrm{ex}} \quad$ temperature at the outer surface

(K)

$\mathrm{T}_{\mathrm{g}}$ temperature of the gas in plasma zone

(K) 


\section{ACCEPTED MANUSCRIPT}

\section{Introduction}

Dielectric barrier discharges (DBD) and corona discharges can be used to produce nonthermal plasmas at atmospheric pressure. Highly reactive species (ozone, excited atoms..) which are generated within such plasmas can be utilized in many applications such as deposition of coatings [1], reactive surface treatments [2] and pollution control [3]. In a DBD reactor, a dielectric material is placed in the discharge gap on at least one metal electrode; this leads to the formation of a large number of filamentary microdischarges of some nanoseconds duration. As a result, highly reactive non equilibrium conditions are obtained. Many experimental and numerical studies have clarified the fundamental processes of such microdischarge formation [4]. At atmospheric pressure, electron temperature is of order of a few $\mathrm{eV}(10000 \mathrm{~K})$ whereas gas temperature is considered to be nearly the ambient temperature. No much attempts have been made to understand the thermal phenomena in a DBD reactor due to the Joule heating of the gas. The main goal of this paper is therefore to develop a simple heat conduction model leading to the definition of a reactor thermal resistance. This model is then used to determine the heat losses in an experimental laboratory reactor with helium or air as working gases. Analysis according to the thermal resistance shows that $86 \%$ of the input power was dissipated to the environment when the flowing gas is helium and that this fraction falls to $42 \%$ in the case where air is the working fluid.

\section{Experimental setup}

\subsection{DBD reactor}

The experimental set-up is shown in Figures 1 and 2. The Dielectric Barrier Discharge reactor $(\mathrm{DBD})$ used exhibits a coaxial geometry with a glass tube $(12.4 \mathrm{~mm}$ in-diameter, 1.8 $\mathrm{mm}$ thickness) as dielectric barrier (Fig.2). The inner electrode, linked to the high voltage, is a $3.2 \mathrm{~mm}$ out-diameter steel tube. The outer electrode, connected to the ground, is a $1 \mathrm{~mm}$ thick 


\section{ACCEPTED MANUSCRIPI}

and $80 \mathrm{~mm}$ (L) long copper tube wrapped around the glass tube. The gap between both electrodes is $4.6 \mathrm{~mm}$. The volume between electrodes in which occurs the discharge, called hereafter the plasma zone (Fig.2), is equal to $9 \mathrm{~cm}^{3}$.

Experiments were carried out at atmopsheric pressure and in a room where the temperature is fixed to $20^{\circ} \mathrm{C}$. The gases used are helium and reconstituted air (Purity $>99,9 \%$ ). The flow rate of gases was fixed to $116 \mathrm{ml} / \mathrm{min}$ (Brook mass flow controller). So, the residence time of gases in the plasma zone is $4.65 \mathrm{~s}$.

In this reactor, no chemical reaction was observed with helium, whereas air leads to ozone and NOx formation $[2,5]$.

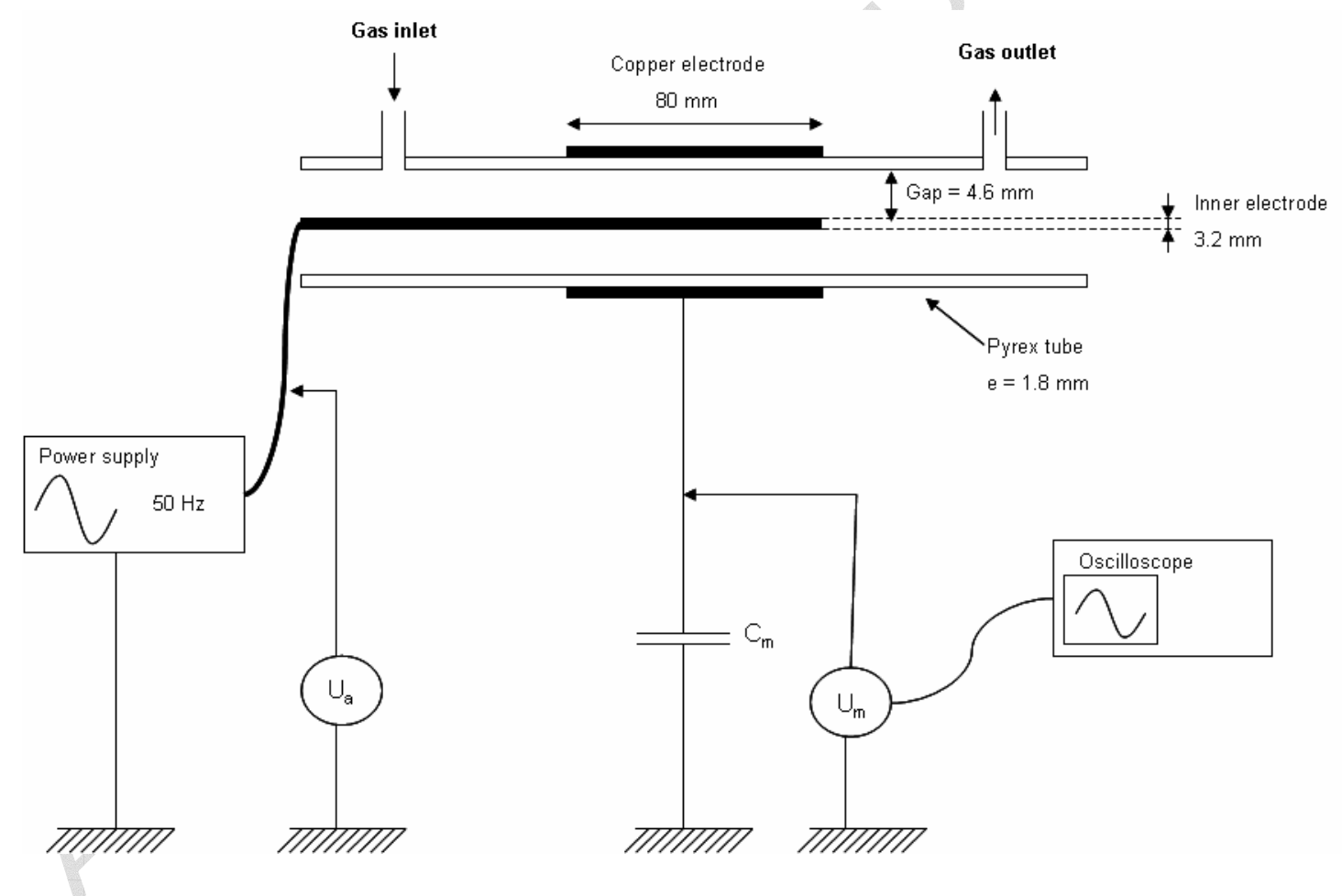

Figure 1. Experimental set-up. 


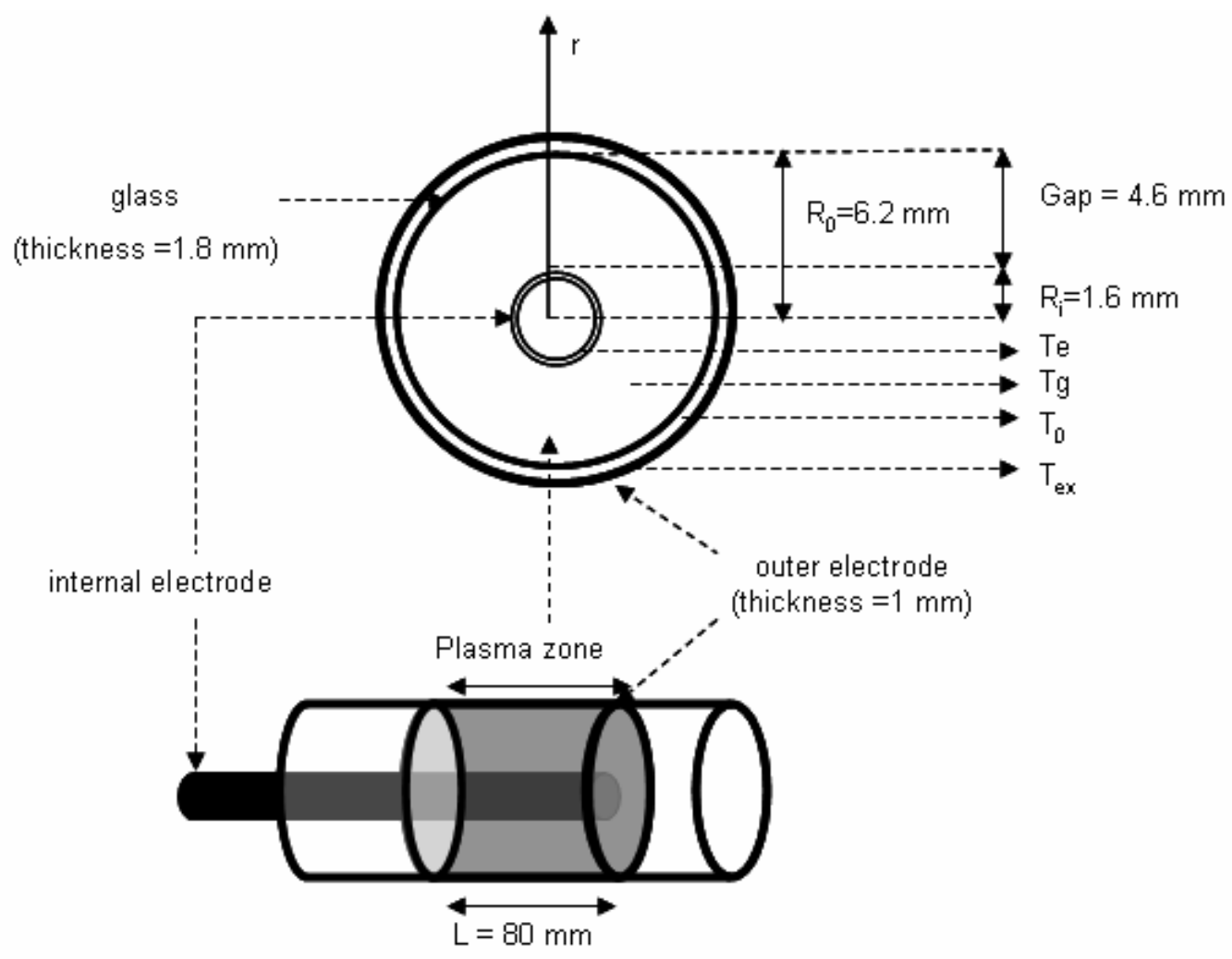

Figure 2. Scheme of DBD reactor with the positions of temperature measurements

\subsection{Electrical Diagnostic}

The electrical discharge was ignited by applying AC high voltage in the range 0 to $40 \mathrm{kV}$ (peak to peak) with a frequency of $50 \mathrm{~Hz}$ (Fig.1). The charge Q (i.e. current integrated over time) was measured from the voltage (Um) across a capacitor $\left(\mathrm{C}_{\mathrm{m}}\right)$ of $560 \mathrm{pF}$ connected in series to the ground electrode. The applied voltage (Ua) was measured with a high voltage probe (Lecroy, PPE, $20 \mathrm{kV}, 100 \mathrm{MHz}$ ). The voltage and charge wave forms were recorded by a digital oscilloscope (Lecroy LT 374L) by averaging 256 scans. When plotting transported electrical charge $\mathrm{Q}$ as a function of the applied voltage (Ua), a typical discharge Lissajous figure is obtained the area of which gives the energy supplied during a period. The input power $(\mathrm{P})$ injected in the DBD reactor was then calculated by multiplying the area by the frequency $(50 \mathrm{~Hz})$ and the capacitance. 


\section{ACCEPTED MANUSCRIPT}

\subsection{Temperature measurement}

In the plasma zone, any metallic device is subjected to electric arc. So, the use of thermocouples is not safe at all. Temperature measurements inside the plasma zone and the central electrode have thus been achieved with optical fibres. The measurements were recorded at a frequency of $0.5 \mathrm{~Hz}$ by means of a specific trade sensor, composed of an Ybifurcated fiber provided with a gallium arsenide (GaAs) chip. Beyond $850 \mathrm{~nm}$, gallium arsenide becomes optically transparent. The bandwidth of that component depends on temperature and varies by an amount of $0.4 \mathrm{~nm} / \mathrm{K}$. The position of the bandwidth, and therefore of temperature, is determined by the spectral detector integrated to the measurement box. Temperature of the outer electrode were measured by a Infra Red pyrometer thermoneter (Raytech, MiniTemp MT4). Temperatures were recorded at different locations in the reactor. In this study, we focus on the temperatures of the internal $\left(T_{e}\right)$ and the external $\left(T_{e x}\right)$ electrodes (Fig 2).

\subsection{Experimental results}

For each power input in the DBD reactor, temperatures measured at different points increase with time and reach a steady state. Figure 3 shows that the steady state temperatures $T_{e}$ and $\mathrm{T}_{\mathrm{ex}}$ increase with the input power as expected whatever the gas used. For the same input power, it can be seen that the temperature levels are higher with air. These experimental steady temperatures will be used in the analytical model developed in the next section. 


\section{ACCEPTED MANUSCRIPT}
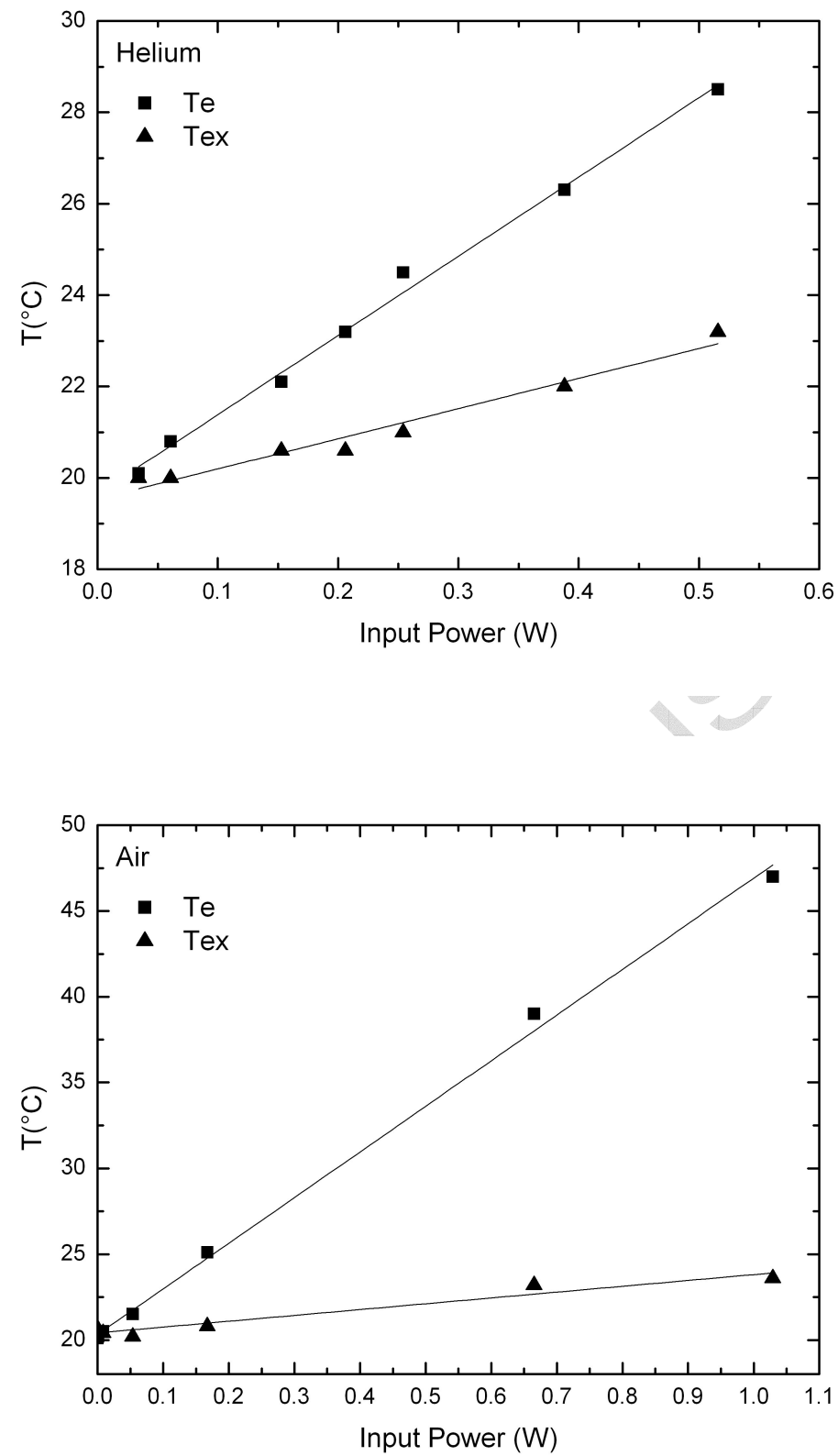

Figure 3. Temperature in the DBD reactor versus the input power with helium and air 


\section{ACCEPTED MANUSCRIPT}

\section{Heat conduction model}

In this section a simplified one dimensional heat conduction model is proposed. The convected heat flux by the flowing gas is neglected due to i) the low mass flow rate used in the experiments and ii) to the fact that the observed axial temperature variation is much lower than the radial temperature variation. We will thus assume that heat is generated in the plasma and that it flows radially to reach the external electrode where it is dissipated by convection and radiative transfer to the environment which is at an ambient temperature. One can of course calculate the heat losses by measuring the temperature of the external electrode and by using appropriate heat exchange coefficient $\mathrm{h}$ and emissivity of the surface. However, these parameters and the heat flow through the wire linking the external electrode to the ground are difficult to estimate. In order to avoid this problem, we have chosen to calculate the heat flux by using the measured temperatures at the two electrodes. Besides, this conduction model can also be used to predict the internal gas temperature and its variation in the radial direction.

\subsection{Radial temperature}

We consider the problem of heat conduction in the annular space enclosed between two coaxial cylinders described in section 2.1. The gap is filled with a gas in which heat is generated with a power per unit volume calculated in the annexe in the form:

$$
p=\frac{A}{r^{2}}
$$

Where $\mathrm{r}$ is the radial coordinate and $\mathrm{A}$ a constant which will be determined later.

The problem is thus governed by the following steady heat equation:

$$
\frac{\lambda}{r} \frac{\partial}{\partial r}\left(r \frac{\partial T}{\partial r}\right)=-\frac{A}{r^{2}}
$$

where $\lambda$ is the thermal conductivity of the fluid. 
The solution is readily obtained as:

$$
T(r)=-\frac{A}{2 \lambda}(\ln r)^{2}+C \ln r+D
$$

The hollow internal electrode (of radius $\mathrm{R}_{\mathrm{i}}$ ) is very thin; we will thus neglect the heat flux flowing along the cross sectional area of this electrode and assume that the following boundary condition holds at the surface of the inner electrode:

$$
\frac{d T}{d r}=0 \quad \text { at } \quad r=R_{i}
$$

This leads to the following expression for the constant C:

$$
C=\frac{A}{\lambda} \ln R_{i}
$$

The constant $\mathrm{D}$ is obtained by using the temperature $\mathrm{T}_{\mathrm{e}}$ at the surface of the internal electrode:

$$
D=T_{e}-\frac{A}{2 \lambda}\left(\ln R_{i}\right)^{2}
$$

Finally, the radial variation of temperature is expressed as follows:

$$
T=T_{e}-\frac{A}{2 \lambda}\left[\ln \left(\frac{r}{R_{i}}\right)\right]^{2}
$$

We will now express the constant A by using the total generated power $\mathrm{P}$ in the plasma zone enclosed between internal and external radius $R_{i}$ and $R_{0}$ and of length $L$ (length of the external electrode) by using the following relation:

$$
\int_{R_{i}}^{R_{o}} 2 \pi p r L d r=P
$$

Therefore, one obtains:

$$
A=\frac{P}{2 \pi L \ln \left(\frac{R_{o}}{R_{i}}\right)}
$$

It is worth mentioning here that $\mathrm{P}$ is the heat generated in the gas. It is thus a fraction of the total input power, the other fraction being used by the inelastic collisions. 


\section{ACCEPTED MANUSCRIPT}

\subsection{Radial Heat loss}

We now consider that the gas is enclosed by a glass tube and the external electrode. If the temperature at the outer surface is $\mathrm{T}_{\mathrm{ex}}$, the total amount of heat flow across this composite envelope can be written as :

$$
P=\frac{T_{o}-T_{e x}}{R_{T}}
$$

Where $\mathrm{R}_{\mathrm{T}}$ is the thermal resistance of the composite envelope and where $\mathrm{T}_{0}$ is the temperature at the inner surface of the glass which writes:

$$
T_{o}=T_{e}-\frac{A}{2 \lambda}\left[\ln \left(\frac{R_{o}}{R_{i}}\right)\right]^{2}
$$

By using equations (9) and (11) we rewrite equation (10) as follows:

$$
P=\frac{T_{e}-T_{e x}-\frac{A}{2 \lambda} \ln \left(\frac{R_{o}}{R_{i}}\right)^{2}}{R_{T}}
$$

Using the expression of $\mathrm{A}$, this can be written:

$$
P=\frac{T_{e}-T_{e x}-\frac{P}{4 \pi \lambda L} \ln \left(\frac{R_{o}}{R_{i}}\right)}{R_{T}}
$$

Rearranging the previous equation, one finally obtains:

$$
P=\frac{T_{e}-T_{e x}}{R_{T}+\frac{1}{4 \pi \lambda L} \ln \left(\frac{R_{o}}{R_{i}}\right)}
$$

One can thus define a thermal resistance $\mathrm{R}_{\mathrm{G}}$ of the annular gas gap as:

$$
R_{G}=\frac{1}{4 \pi \lambda L} \ln \left(\frac{R_{o}}{R_{i}}\right)
$$

In many situations, the composite thermal resistance is small compared to the gas resistance.

One then can simply write: 


$$
P \approx \frac{T_{e}-T_{e x}}{\frac{1}{4 \pi \lambda L} \ln \left(\frac{R_{o}}{R_{i}}\right)}
$$

By measuring the temperatures of the internal and external electrodes, one can thus use equation (14) to find the heat loss by conduction.

\section{Results}

The calculated heat losses are presented on table $1(\mathrm{He})$ and on table 2 (Air) together with the applied voltage, the total electric input power, the internal electrode $\left(T_{e}\right)$ and external electrode $\left(\mathrm{T}_{\mathrm{ex}}\right)$ temperatures. In the last column is given the percentage $\eta$ of the total input power which is dissipated by heat conduction. It is seen, as expected, that the heat losses increase with increasing voltage and thus with increasing input power. The thermal conductivity of $\mathrm{He}\left(0.16 \mathrm{~W} / \mathrm{m}^{\circ} \mathrm{C}\right)$ being higher than that of air $\left(0.025 \mathrm{~W} / \mathrm{m}^{\circ} \mathrm{C}\right)$, heat $\operatorname{loss}$ is greater with helium and consequently temperature levels are higher in air. The fraction of the input power that is dissipated decreases with the input power. This decrease is more pronounced in the case of helium for which $\eta$ is higher than $86 \%$. On the other hand, the fraction of the input power is smaller when air is the flowing gas and globally its variation with the input power is less pronounced. This is due to the development of chemical reactions in air. Therefore, a larger fraction of the input power is used by these chemical reactions and the heat generated by electron and ion collisions is much lower.

Table 1: Experimental results and calculated heat losses for Helium

\begin{tabular}{cccccc}
\hline $\begin{array}{c}\text { Voltage } \\
\mathrm{kV}\end{array}$ & $\begin{array}{c}\text { Input power } \\
\mathrm{W}\end{array}$ & $\begin{array}{c}\text { Te } \\
{ }^{\circ} \mathrm{C}\end{array}$ & $\begin{array}{c}\text { Tex } \\
{ }^{\circ} \mathrm{C}\end{array}$ & $\begin{array}{c}\text { Heat loss } \\
\mathrm{W}\end{array}$ & $\begin{array}{c}\eta \\
\%\end{array}$ \\
\hline 19.4 & 0.51 & 28.5 & 23.2 & 0.44 & 86 \\
16.2 & 0.39 & 26.3 & 22.0 & 0.36 & 92 \\
12.6 & 0.28 & 24.2 & 21.0 & 0.27 & 97 \\
\hline
\end{tabular}


Table 2: Experimental results and calculated heat losses for Air

\begin{tabular}{cccccc}
\hline $\begin{array}{c}\text { Voltage } \\
\mathrm{kV}\end{array}$ & $\begin{array}{c}\text { Input power } \\
\mathrm{W}\end{array}$ & $\begin{array}{c}\text { Te } \\
{ }^{\circ} \mathrm{C}\end{array}$ & $\begin{array}{c}\text { Tex } \\
{ }^{\circ} \mathrm{C}\end{array}$ & $\begin{array}{c}\text { Heat loss } \\
\mathrm{W}\end{array}$ & $\begin{array}{c}\eta \\
\%\end{array}$ \\
\hline 20.3 & 1.03 & 47.0 & 23.6 & 0.43 & 42 \\
17.6 & 0.67 & 39.0 & 23.2 & 0.29 & 44 \\
13.7 & 0.17 & 25.1 & 20.8 & 0.08 & 47 \\
\hline
\end{tabular}

In order to calculate the gas temperature, one must remember that the total generated power $\mathrm{P}$ is equal to the total electric input power (given in table 1 and table 2) multiplied by the parameter $\eta$ One can then deduce constant A given by equation (9) and use measured values of internal electrode temperature to obtain the gas temperature by using equation (7). We will focus here in the excess temperature $\Delta=\mathrm{Tg}-\mathrm{Ta}$ where $\mathrm{Tg}$ and $\mathrm{Ta}$ are gas and ambient temperature. We present on Fig. 4 and Fig.5, typical variations of $\Delta$ for air and helium respectively. It can be seen that the temperature gradient is higher with air as expected. This is due to its lower thermal conductivity. Finally, we have compared measured gas temperatures at an adimensional radial temperature $\mathrm{r} / \mathrm{Ri}=2.4$ to the theoretical values given by the model and found that the maximum error was lower than 5\%. These results assess the correctness of the proposed simple model.

\section{Conclusion}

The heat generated in a DBD reactor by elastic collisions and which is lost by conduction across the gas layer and the composite envelope of the reactor has been calculated by a simplified model. On the basis of this conduction model a reactor thermal resistance is established. By using electrode temperatures measurements, it has been shown that the fraction of the input power that is dissipated depends highly on the gas nature and decreases with increasing input power. The percentage of the input power that is dissipated to the environment by convection and radiative transfer is within a range between 0.86 and 1 when 
helium is the flowing gas. This percentage falls to a range between 0.42 and 0.47 in the case where air is the flowing gas. We believe that this kind of models can be useful for obtaining optimal thermal conditions and the percentage of the input power that is used by the chemical reactions. Finally, transient process can also be considered. Such an unsteady model is underway and will be published soon.

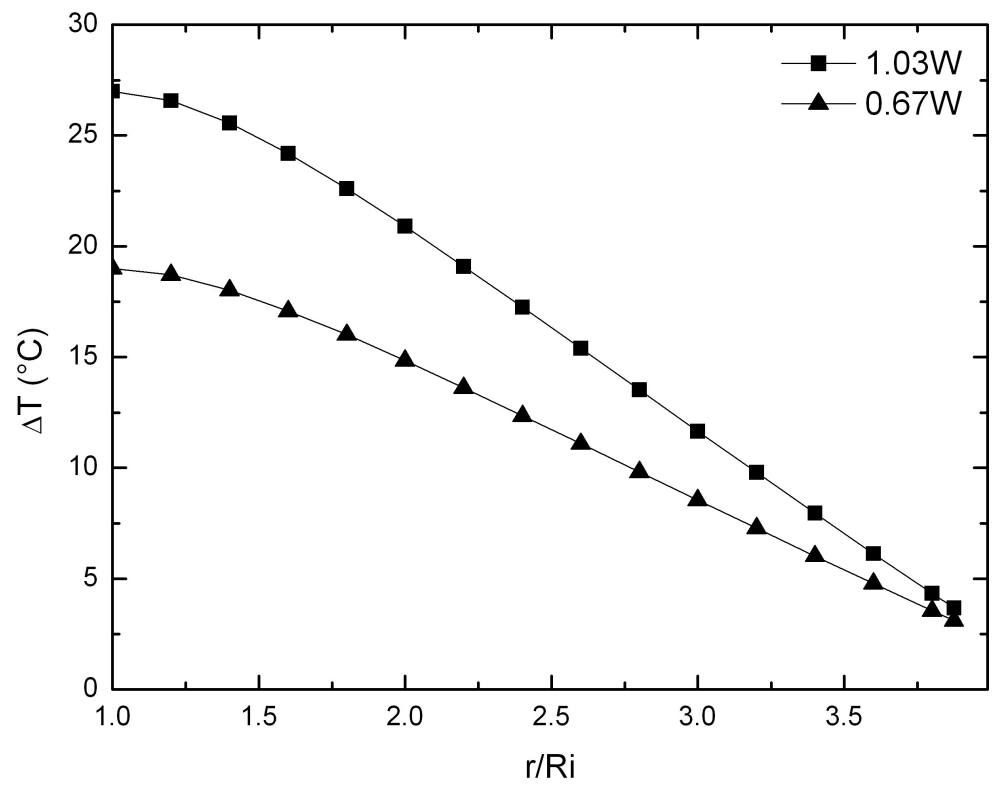

Figure. 4. Excess temperature with air for an electric power of $1.03 \mathrm{~W}(\boldsymbol{\square})$ and $\mathrm{P}=0.67 \mathrm{~W}(\boldsymbol{\Delta})$ 


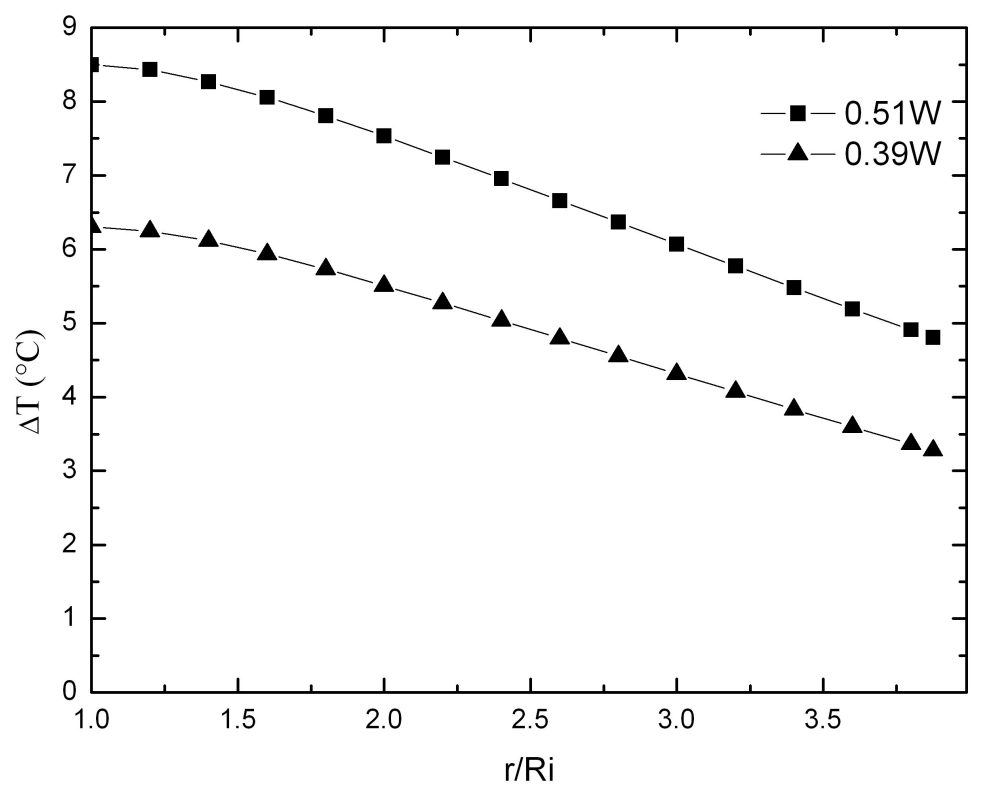

Figure.5. Excess temperature with helium for an electric power of $0.51 \mathrm{~W}(\mathbf{\square})$ and $\mathrm{P}=0.39$ $\mathrm{W}(\boldsymbol{\Delta})$

\section{References}

[1] A. Fridman, A. Chirokov and A. Gutsol, "Non thermal atmospheric pressure discharges”, J. Phys. D: Appl. Phys, 38 (2005), R1-R24

[2] Z. Falkenstein and J. J. Coogan, " Microdischarge behaviour in the silent discharge of nitrogen-oxygen and water-air mixtures," Journal of Physics D: Applied Physics, 30 (1997), 817.

[3] Eliasson B. , Hirth M. and Kogelschatz U., J. Phys. D: Appl. Phys., 20 (1987) 1421

[4] B.Eliasson and U.Kogelschatz,IEEE Trans.Plasma Sci. 19,309 (1991)

[5] C. Ayrault, J. Barrault, N. Blin-Simiand, F. Jorand, S. Pasquiers, A. Rousseau, J.M. Tatibouët, Oxidation of 2-heptanone in air by a DBD-type plasma generated within a honeycomb monolith supported Pt-based catalyst, Catalysis Today 89,(2004), 75-81. 


\section{Annexe}

Since net space charge is negligible in plasma, the governing equation for the voltage writes:

$$
\frac{1}{r} \frac{\partial}{\partial r}\left(r \frac{\partial V}{\partial r}\right)=0
$$

The general evolution of the voltage is then given by:

$$
V=C_{1} \log (r) \dashv C_{2}
$$

Where $\mathrm{C} 1$ and $\mathrm{C} 2$ are constants of integration.

The electric field is obtained by taking the gradient of the voltage :

$$
E=-\frac{\partial V}{\partial r}=-\frac{C_{1}}{r}
$$

Finally, the power per unit volume generated which is proportional to the square of the electric field is deduced as follows:

$$
p=\frac{A}{r^{2}}
$$

Constant A will be determined by performing a heat balance. 